\title{
Neuregulin-4, an Adipokine, as a Residual Risk Factor of Atherosclerotic Coronary Artery Disease
}

\author{
Tatsuyuki Sato, ${ }^{1}$ MD and Shun Minatsuki, ${ }^{1}$ MD
}

(Int Heart J 2019; 60: 1-3)

$\mathrm{O}$ ver the past 30 years, treatment strategies for classical risk factors of coronary artery diseases (CAD) such as hypertension, hypercholesteremia, and diabetes mellitus have advanced remarkably. However, ischemic heart diseases still remain the leading cause of heart failure and cardiovascular death worldwide, and identification and treatment of the residual risk factors is essential. ${ }^{1)}$ Adipokines are gaining attention as residual risk factor candidates and as novel treatment targets of CAD. The association between adipokines such as interleukin-6, adiponectin, leptin, and tumor necrosis factor alfa and CAD is being studied. In addition, the drugs that affect the adipokines are also being examined as potential therapeutics. ${ }^{2-8)}$

A recently identified adipokine, neuregulin-4 (Nrg4), is one of the four neuregulin family proteins: cell-cell signaling proteins that possess an EGF-like domain and bind to the ErbB family tyrosine kinase receptors. ${ }^{9)} \mathrm{Nrg} 4$ was first identified as a neuregulin family protein enriched in the pancreas, ${ }^{10)}$ but recently Rosell, et al. reported that Nrg4 is highly expressed in brown adipose tissues (BAT) as an adipokine; its role in atherosclerosis has been gaining attention. ${ }^{11)}$ Jiang, et al. showed that serum Nrg4 levels were lower in patients with metabolic syndromes, and Cai, et al. showed that serum Nrg4 levels inversely correlate with carotid intima-media thickness. ${ }^{12,13)}$

\section{Article p.45}

In this issue of International Heart Journal, Tian, et al. have expanded these previous findings to include the association between serum Nrg4 levels and the presence and complexity of CAD. ${ }^{14}$ The authors reported for the first time that serum $\mathrm{Nrg} 4$ levels were significantly lower in patients with CAD. Logistic regression analysis revealed that serum Nrg4 level was a predictor for the presence of CAD, independent of the patients' blood pressure, low density lipoprotein cholesterol levels, and smoking status, thus indicating serum Nrg4 as a possible residual risk factor. They also showed that a higher SYNTAX score was associated with lower serum Nrg4 levels among patients with CAD. In their analyses, the serum $\mathrm{Nrg} 4$ level did not correlate with age, body mass index, low density lipoprotein cholesterol levels, high-sensitivity Creactive protein, or glycosylated hemoglobin A1c, but did correlate with the SYNTAX score, suggesting that serum $\mathrm{Nrg} 4$ is a predictor of CAD severity. ROC curve analysis revealed that serum $\mathrm{Nrg} 4$ levels had both high sensitivity and specificity for the identification of patients with severe CAD. The present study suggested the potential of $\mathrm{Nrg} 4$ as a residual risk factor and as a novel therapeutic target for CAD. ${ }^{14)}$

However, two important questions remain to be answered in order to understand the effect of serum $\mathrm{Nrg} 4$ on CAD: (1) is there any causal relationship between the increased level of serum Nrg4 and the presence and the severity of CAD; and (2) what accounts for the changes in serum Nrg4 levels and what is the possible intervention to alter the levels?

Although the present study and the aforementioned population studies only show an association between Nrg4 and CAD with no information on the causality, data from a rodent model suggest that serum $\mathrm{Nrg} 4$ affects the formation of atherosclerosis. Clement, et al. showed that ErbB4, the receptor of $\mathrm{Nrg} 4$, increased dramatically in the endothelium of a rat carotid artery injury model. ${ }^{15)}$ In the same study, treatment with neuregulin-1 (a member of the neuregulin family proteins which can also activate ErbB4) attenuated neointima formation. ${ }^{15)}$ Signaling via ErbB4 tyrosine kinase receptors shows an anti-apoptotic effect via stimulation of the Akt/PI3K pathway, ${ }^{16)}$ which reportedly inhibits endothelial cell apoptosis and prevents the progression of atherosclerosis. ${ }^{17,18)}$ These indirect findings are not conclusive, however, and further human cohort studies and biological studies are therefore required.

The mechanisms of the regulation of serum Nrg4 levels and the possible therapeutics to increase that level are unknown. Nrg4 is highly expressed in BAT, and the amino acid sequence of Nrg4 codes a transmembrane domain and an EGF-like domain, with a putative proteolytic cleavage site in between, suggesting that the cleavage is required for the formation of mature secretory $\mathrm{Nrg} 4 .^{10)}$

From the ${ }^{1}$ Department of Cardiovascular Medicine, Graduate School of Medicine, The University of Tokyo, Tokyo, Japan.

Address for correspondence: Tatsuyuki Sato, MD, Department of Cardiovascular Medicine, Graduate School of Medicine, The University of Tokyo, 7-3-1

Hongo, Bunkyo-ku, Tokyo 113-8655, Japan. E-mail: tatsuyusatou-tky@umin.ac.jp

Received for publication November 15, 2018. Revised and accepted November 15, 2018.

doi: $10.1536 /$ ihj. $18-654$

All rights reserved by the International Heart Journal Association. 
Brown adipose tissue

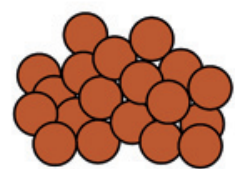

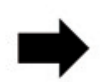

Endothelial cell apoptosis $\uparrow$

\section{Coronary artery disease}

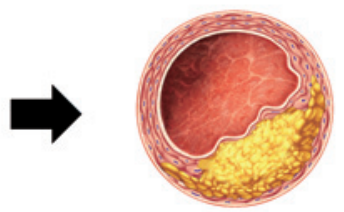

Amount $\downarrow$

Nrg-4 expression $\downarrow$

Nrg-4 secretion $\downarrow$

Figure A possible model of the effect of Nrg-4 on coronary artery disease. Alterations in the amount of brown adipose tissue, the expression of Nrg-4 within the brown adipose tissue, or the secretion of Nrg-4 from the adipose tissue may contribute to the decreased serum Nrg-4 levels, resulting in increased endothelial cell apoptosis and coronary artery disease. Nrg-4, Neuregulin-4.

The key determinant factor of serum Nrg4 levels may be the amount of BAT, the level of $\mathrm{Nrg} 4$ expression within the BAT, the proteolytic cleavage and secretion of the Nrg4 from the BAT, or the removal of Nrg4 from systemic circulation, and drugs that can modulate each factor have the potential to increase serum Nrg4 levels (Figure).

As a drug used to increase the amount of BAT, the PPAR $\gamma$ agonist rosiglitazone has been identified $;{ }^{19)}$ the drug also reportedly restores Nrg4 expression in adipocytes. ${ }^{20)}$ However, although there are many conflicting results, the drug has safety concerns especially for congestive heart failure patients and thus its use in patients with CAD may require caution. ${ }^{21)}$ Recently, a cyclin-dependent kinase inhibitor, roscovitine, was reported to induce browning of the adipose tissue, enhance energy expenditure, and prevent diet-induced obesity. ${ }^{22)}$ Phase 2 clinical studies have been completed on roscovitine for nasopharyngeal and non-small cell lung cancer, and human trials on non-cancer diseases such as rheumatoid arthritis are ongoing. ${ }^{23,24)}$ The medical community is awaiting increased research into CAD.

As a drug to increase the level of $\mathrm{Nrg} 4$ expression within BAT, beta 3-adrenoceptor (B3AR) agonists have been reported. ${ }^{25)} \mathrm{B} 3 \mathrm{AR}$ agonists were investigated as potential anti-obesity drugs in the 1990s, but the low selectivity and bioavailability of the old B3AR agonists hindered the expansion of the research. ${ }^{26}$ ) The recently approved B3AR agonist mirabegaron achieved satisfactory bioavailability with high specificity; it reportedly activates human BAT thus raising expectations for future treatment. ${ }^{27)}$

The present study provides important knowledge about the association between serum Nrg4 levels and CAD. ${ }^{14)}$ Further research on this adipokine may expand our understanding of the pathophysiology of atherosclerosis and lead to the development of new therapeutics.

\section{Disclosures}

\section{Conflicts of interest: None.}

\section{References}

1. Benjamin EJ, Virani SS, Callaway CW, et al. American Heart
Association Council on Epidemiology and Prevention Statistics Committee and Stroke Statistics Subcommittee. Heart Disease and Stroke Statistics-2018 Update: A Report From the American Heart Association. Circulation 2018; 137: e67-492.

2. Kuo LT, Yang NI, Cherng WJ, et al. Serum interleukin-6 levels, not genotype, correlate with coronary plaque complexity. Int Heart J 2008; 49: 391-402.

3. Ridker PM, Rifai N, Stampfer MJ, Hennekens CH. Plasma concentration of interleukin- 6 and the risk of future myocardial infarction among apparently healthy men. Circulation 2000; 101: 1767-72.

4. Kajikawa Y, Ikeda M, Takemoto S, Tomoda J, Ohmaru N, Kusachi S. Association of circulating levels of leptin and adiponectin with metabolic syndrome and coronary heart disease in patients with various coronary risk factors. Int Heart J 2011; 52: 17-22.

5. Kawagoe J, Ishikawa T, Iwakiri H, Date H, Imamura T, Kitamura K. Association between adiponectin production in coronary circulation and future cardiovascular events in patients with coronary artery disease. Int Heart J 2014; 55: 239-43.

6. Sattar N, Wannamethee G, Sarwar N, et al. Adiponectin and coronary heart disease: a prospective study and meta-analysis. Circulation 2006; 114: 623-9.

7. Kleveland O, Kunszt G, Bratlie M, et al. Effect of a single dose of the interleukin-6 receptor antagonist tocilizumab on inflammation and troponin $\mathrm{T}$ release in patients with non-ST-elevation myocardial infarction: a double-blind, randomized, placebocontrolled phase 2 trial. Eur Heart J 2016; 37: 2406-13.

8. Orrem HL, Nilsson PH, Pischke SE, et al. IL-6 Receptor Inhibition by Tocilizumab Attenuated Expression of C5a Receptor 1 and 2 in Non-ST-Elevation Myocardial Infarction. Front Immunol 2018; 9: 2035.

9. Falls DL. Neuregulins: functions, forms, and signaling strategies. Exp Cell Res 2003; 284: 14-30.

10. Harari D, Tzahar E, Romano J, et al. Neuregulin-4: a novel growth factor that acts through the ErbB-4 receptor tyrosine kinase. Oncogene 1999; 18: 2681-9.

11. Rosell M, Kaforou M, Frontini A, et al. Brown and white adipose tissues: intrinsic differences in gene expression and response to cold exposure in mice. Am J Physiol Endocrinol Metab 2014; 306: E945-64.

12. Jiang J, Lin $\mathrm{M}, \mathrm{Xu} \mathrm{Y}$, et al. Circulating neuregulin 4 levels are inversely associated with subclinical cardiovascular disease in obese adults. Sci Rep 2016; 6: 36710.

13. Cai C, Lin M, Xu Y, Li X, Yang S, Zhang H. Association of circulating neuregulin 4 with metabolic syndrome in obese adults: a cross-sectional study. BMC Med 2016; 14: 165.

14. Tian QP, Liu ML, Tang CS, Xue L, Pang YZ, Qi YF. Association of circulating neuregulin-4 with presence and severity of coronary artery disease. Int Heart J 2019; 60: 45-9.

15. Clement CM, Thomas LK, Mou Y, Croslan DR, Gibbons GH, Ford BD. Neuregulin-1 attenuates neointimal formation follow- 
ing vascular injury and inhibits the proliferation of vascular smooth muscle cells. J Vasc Res 2007; 44: 303-12.

16. Bernard JK, McCann SP, Bhardwaj V, Washington MK, Frey MR. Neuregulin-4 is a survival factor for colon epithelial cells both in culture and in vivo. J Biol Chem 2012; 287: 39850-8.

17. Tie G, Yan J, Yang Y, et al. Oxidized low-density lipoprotein induces apoptosis in endothelial progenitor cells by inactivating the phosphoinositide 3-kinase/Akt pathway. J Vasc Res 2010; 47: 519-30.

18. Qin M, Luo Y, Meng XB, et al. Myricitrin attenuates endothelial cell apoptosis to prevent atherosclerosis: An insight into PI3K/ Akt activation and STAT3 signaling pathways. Vascul Pharmacol 2015; 70: 23-34.

19. Wilson-Fritch L, Nicoloro S, Chouinard M, et al. Mitochondrial remodeling in adipose tissue associated with obesity and treatment with rosiglitazone. J Clin Invest 2004; 114: 1281-9.

20. Chen Z, Wang GX, Ma SL, et al. Nrg4 promotes fuel oxidation and a healthy adipokine profile to ameliorate diet-induced metabolic disorders. Mol Metab 2017; 6: 863-72.

21. Florez H, Reaven PD, Bahn G, et al; VADT Research Group. Rosiglitazone treatment and cardiovascular disease in the Veterans Affairs Diabetes Trial. Diabetes Obes Metab 2015; 17: 949 -
55 .

22. Wang H, Liu L, Lin JZ, Aprahamian TR, Farmer SR. Browning of White Adipose Tissue with Roscovitine Induces a Distinct Population of UCP1(+) Adipocytes. Cell Metab 2016; 24: 83547.

23. Whittaker SR, Mallinger A, Workman P, Clarke PA. Inhibitors of cyclin-dependent kinases as cancer therapeutics. Pharmacol Ther 2017; 173: 83-105.

24. Zhelev N, Trifonov D, Wang S, Hassan M, Serafi EL, Mitev V. From Roscovitine to CYC202 to Seliciclib - from bench to bedside: discovery and development. Biodiscovery 2013; 10: 1 .

25. Poekes L, Gillard J, Farrell GC, Horsmans Y, Leclercq IA. Activation of brown adipose tissue enhances the efficacy of caloric restriction for treatment of nonalcoholic steatohepatitis. Lab Invest 2018 (in press).

26. Arch JR. The beta 3-adrenergic system and beta 3-adrenergic agonists. Rev Endocr Metab Disord 2001; 2: 385-93.

27. Cypess AM, Weiner LS, Roberts-Toler C, et al. Activation of human brown adipose tissue by a $\beta 3$-adrenergic receptor agonist. Cell Metab 2015; 21: 33-8. 